\title{
Future Water Availability Under Representative Concentration Pathways Scenario in Baro Basin, Ethiopia
}

\author{
Tolossa Negassa Ebissa \\ Department of Civil Engineering, College of Engineering and Technology, Mettu University, Mettu, Ethiopia
}

\section{Email address:}

tolossanegassa825@gmail.com

\section{To cite this article:}

Tolossa Negassa Ebissa. Future Water Availability Under Representative Concentration Pathways Scenario in Baro Basin, Ethiopia. Journal of Water Resources and Ocean Science. Vol. 10, No. 2, 2021, pp. 26-38. doi: 10.11648/j.wros.20211002.12

Received: November 17, 2020; Accepted: April 12, 2021; Published: April 26, 2021

\begin{abstract}
The objective in this study was to assess future water availability in the upper part of the Baro basin in Southwest Ethiopia through the Representative Concentration Pathway (RCP 4.5) scenario. HBV-96 rainfall-runoff model was calibrated and validated for historical records of streamflow. The estimated NSE and RVE values are 0.91 and $-6.76 \%$ during calibration period (1996-2002) and validation period (2003-2005) values are 0.72 and $9.78 \%$ respectively. Dynamically downscaled climate model outputs were obtained from four models through the CORDEX-Africa program. The four climate models were evaluated using a suite of statistical measures such as bias, Root Mean Squared Error (RMSE) and Coefficient of Variation (CV). The bias of the simulated rainfall varies between $-4.20 \%$ and $-25.39 \%$ suggesting underestimation. In terms of bias, ECEarth performs best while HadGEM2-ES performs worst. In terms of RMSE, MPI-ESM-LR performs worst while CM5A-MR performs best. All the four GCMs projections showed that the maximum temperature will likely increase by $2.08^{\circ} \mathrm{C}(\mathrm{MPI}-$ ESM-LR) to $2.52^{\circ} \mathrm{C}$ (CM5A-MR) and minimum temperature will also likely increase by $1.65^{\circ} \mathrm{C}$ (EC-Earth) to $2.78^{\circ} \mathrm{C}$ (HadGM2-ES) in the Baro basin in medium-term (2041-2070) for the RCP4.5 scenario. However, the annual rainfall amount will likely decrease by $7.34 \%$ (CM5A-MR) to $17.42 \%$ (HaDGEM2-ES) and with a likely increase in annual potential evapotranspiration. The maximum streamflow reduction was projected for the rainy season (Kiremt) by up to $28.36 \%$ (CM5AMR). The annual streamflow is projected to decline by up to $35.2 \%$ during $2050 \mathrm{~s}$. The findings of this study indicate that climate change under the RCP4.5 scenario will have a significant implication to water availability in the Baro basin.
\end{abstract}

Keywords: Climate Change Impact, RCP, Streamflow, HBV-96 Model, Baro Basin

\section{Introduction}

The latest IPCC scenarios (AR5) projects global temperature rises by 1.4 to $5.8^{\circ} \mathrm{C}$ by 2100 . This lead to altered temperature and precipitation at regional and subbasin levels. Changes in local climate may affect frequency and intensity of extreme weather events which will have a major impact on natural and human systems [14].

In this study, the hydrological impacts of climate change on the availability of water surface resources was evaluated for the Baro river basin in western Ethiopia using Representative Concentration Pathways (RCP 4.5) scenario. Baro river basin is one of the largest perennial tributaries of the White Nile. It crosses the Gambela region which is the most vulnerable regions of Ethiopia to the adverse impacts of climate change, since livelihood depends on farming and livestock keeping [9]. Finding of this study will provide information for future water resources management in the area and also contribute to the scientific literature on climate change impact studies.

The International Panel on Climate Change finding indicates that developing countries such as Ethiopia are the most vulnerable to climate variability and change due to less adjustment of economic structure and highly dependent agricultural economy. Gambela has been strongly affected by recurrent flood, drought and famine. Agricultural activities in arid and semi-arid parts of the country are highly depend on the rainfall.

As revised literature in the study area, shows limited studies have been conducted in Baro basin with respect to the impact of climate change on water availability. Kebede, A. Suggested that GCM and old climate scenario SRES for the analysis over Baro-Akobo River basin precipitation does not show systematic increase or decrease while, temperature is 
projected to increase in the basin [10]. The author suggested further research using multiple climate models to properly assess future projections. The previous studies for BaroAkobo River basin is used only GCM outputs for old scenario (SRES). However, outputs of regional climate models (RCMs) are made readily available for the new RCP scenarios and must be evaluated for the Baro basin.

In addition, the previous studies used SRES climate scenario while very few studies used the newly developed representative concentration pathway scenario [9, 10, 14]. Previous studies used single or very few climate models which makes it difficult to be conclusive. Therefore additional studies using outputs of multiple climate models are needed to understand the uncertainties of climate change projections.

The main objective of this study is to investigate the future water availability under representative concentration pathways scenario in the Baro river basin. The specific objective of the study area is to evaluate the accuracy of the simulated rainfall by the climate models. The second one is to assess the possible impacts of the climate change on precipitation, temperature and evapotranspiration and the third is to evaluate how streamflow of Baro basin will be affected by climate change.

\section{Description of Study Area}

The study was conducted at Baro basin, which is in the southwest of Ethiopia and which is one of the sub-basins of Baro-Akobo River basin (Figure 1). The Baro basin is geographically located between latitudes of $7^{\circ} 27^{\prime} 35.33^{\prime \prime}$ and $9^{\circ} 23^{\prime} 12.42^{\prime \prime} \mathrm{N}$ and longitudes of $34^{\circ} 31^{\prime} 53.51^{\prime \prime}$ and $36^{\circ} 16^{\prime}$ $18.64 "$ E. It has an estimated total area of $23,409 \mathrm{~km}^{2}$ at Gambela gauging station.

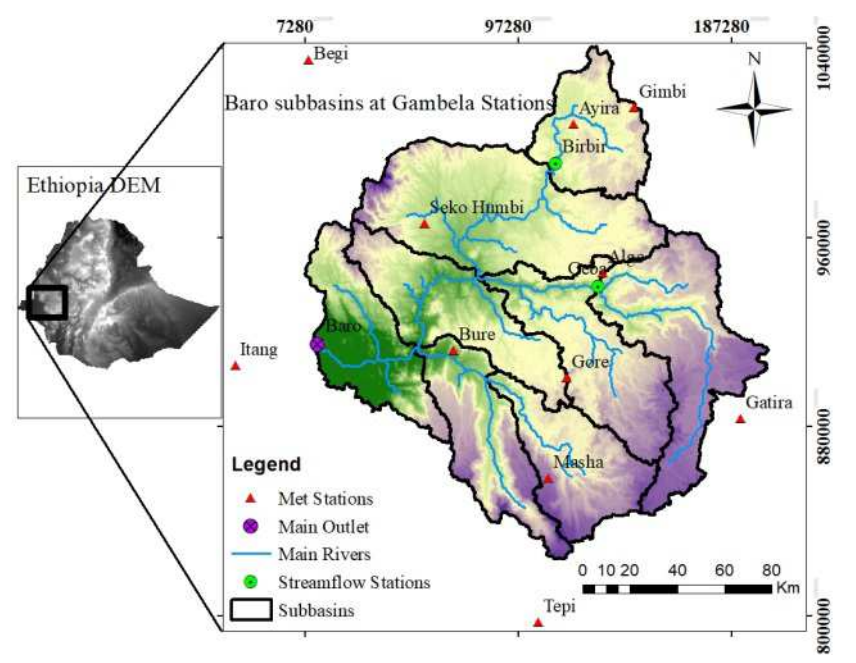

Figure 1. Location map of the study area.

In this study, the basin area is processed from SRTM DEM. The Baro river is created by the confluence of the Birbir and Geba rivers, east of Metu in the Illubabor Zone of the Oromia Region. In this thesis the impact of climate change and future water availability on this river is assessed.

\section{Materials and Methods}

\subsection{Land Use/Land Cover}

Land use/land cover the watershed is mostly covered by forest $(66.09 \%)$. The remaining is covered with cropland $(28.30 \%)$, Woodland and Grassland $(2.42 \%)$, Shrubland $(2.07 \%)$, Wetland $(0.05 \%)$, Water Body $(0.13 \%)$, Settlement $(0.12 \%)$, bare soil $(0.02 \%)$, Rock Outcrop $(0.78 \%)$ and Lava Flow $(0.02 \%)$.

\subsection{Soil}

The soil type of the study area is covered with Gleysols, Haplic luvisols, chromic luvisols, Eutric Leptosols, Eutric Vertisiols and Planosols soil types.

\subsection{Data Sources and Availability}

The datasets for the study was collected from relevant sources. These data include meteorological data, stream flow data, land use/land cover map, DEM and soil map. Arc GIS 10.3 used to delineate the catchment of the study area, HBV96 software used to develop rainfall-runoff model, SRTM $30 \times 30 \mathrm{~m}$ DEM data is used as an input for ArcGIS software for catchment delineation and estimation of catchment characteristic, hydrological and metrological data and etc.

The climate data are accessed from https://esgf data.dkrz.de/projects/esgf-dkrz/. The spatial grid resolutions of all CORDEX-Africa RCMs were set to longitude $0.44^{\circ}$ and latitude $0.44^{\circ}$ using a rotated pole system coordinate. These models operate over an equatorial domain with a quasi-uniform resolution of approximately $50 \mathrm{~km}$ by $50 \mathrm{~km}$. The components of the model are based on the Representative Concentration Pathways (RCP) and quality controlled may be used (https://climate4impact.eu/impactportal/data/esgfsearch.jsp) for the Representative Concentration Pathway scenario (RCP 4.5) projection scenario.

\subsection{Data Quality Analysis}

\subsubsection{Bias Correction}

A power transformation, corrects nonlinearly for the coefficient of variation as well as the mean of the precipitation. For power transformation, correction factors are computed from the statistics of the observed and simulated variables. The principle of this method shows the mean and standard deviation of the daily precipitation data becoming equal to those of the observed data [12]. In this nonlinear correction method each daily precipitation amount $P$ is transformed to a corrected $P^{*}$ using:

$$
P^{*}=a P^{b}
$$

where: $P^{*}$ is the bias corrected daily precipitation, $P$ is the uncorrected daily precipitation and $a$ and $b$ are the transformation coefficients. 
The determination of the $b$ parameter is done iteratively, for areal of each grid box in each month, until the coefficient of variation of the corrected RCM daily precipitation time series matches that of the observed precipitation time series. Then the parameter $a$ is determined such that the mean of the transformed daily values corresponds with the observed mean. Estimation of $a$ and $b$ was made on monthly basis for the time period 1985 to 2005 .

The bias correction for temperature differs from that of precipitation. The correction of temperature only involves shifting and scaling to adjust the mean and variance can be computed by:

$$
\mathrm{T}^{*}=\overline{\mathrm{T}}+\frac{\sigma\left(\mathrm{T}_{\mathrm{o}}\right)}{\sigma\left(\overline{\mathrm{T}}_{\mathrm{R}}\right)}\left(\mathrm{T}_{\mathrm{R}}-\overline{\mathrm{T}}_{\mathrm{o}}\right)
$$

where: $T^{*}$ bias corrected daily future temperature; $\mathrm{T}_{\mathrm{R}}$ the uncorrected daily temperature from RCM; $\bar{T}_{o}$ is the observed daily average temperature; $\bar{T}_{R}$ is the corresponding basin mean temperature obtained from RCM. In this equation an over bar denotes the mean over the considered period and $\sigma$ the standard deviation.

\subsubsection{Missing Value Estimation}

The missing values for the rainfall data are filled by using second degree inverse distance weighted (IDW) interpolation method. IDW estimate is more influenced by nearby measurements than that by far-away measurements The inverse distance weighted (IDW) interpolation method was used to convert station rainfall amounts into sub-basin amounts. Inverse Distance Weighting assigns weights to neighboring observed values based on distance to the interpolation location and interpolated value is the weighted average of the observations. The weights are equal to the reciprocal of the distance or some power of the reciprocal of the distance of the estimator stations from the estimated stations. The same procedure and methods were used to estimate the missed value of temperature data.

\subsubsection{Data Quality, Homogeneity and Consistency Test}

The consistency of observed rainfall was tested by doublemass curve technique. In double mass curve analysis the cumulated rainfall for each station are plotted against accumulated rainfall group stations. This implies that, if their plot graph is a straight line they are consistent. The relocation of rain gauge station, land use changes, adjustments in instruments and observational problems inconsistency of the rainfall data would be felt from the time the significant change took place.

The data is inconsistent by looking the double mass curve, when the plotted graph of cumulated rainfall for each station against accumulated rainfall for group stations over the same period of time is not a straight line, which bends at particularly period of time due to change rainfall station recording in rain gauge type. To check the consistency of the rainfall data, double mass curve was plotted. Cumulative precipitation of individual station was plotted against the cumulative rainfall of all the stations.

\subsubsection{Areal Rainfall Estimation}

In this study, after filling missed rainfall data, the point rainfall data from multiple stations was converted to catchment-averaged rainfall by using Thiessen polygon method. This method was selected arbitrary as there was not solid reason to select others methods. However, the method requires representative rain gauges distribution in for the study area. The daily areal rainfall is calculated from the daily point measurement of rainfall inside the catchment. Theissen's polygon method was applied to determine average areal rainfall for the eight sub-basins. Usually, sub-basin are obtained by the drainage network obtained from a DEM, on the basis of steepest directions. The Thiessen polygon approach gives weight to station data in proportion to the space between the stations and can easily create polygon from point. This method assigns weights for each station by drawing the perpendicular lines that cross the line that connects adjacent stations using ArcGIS 10.3. The rainfall amount of each station is multiplied by ratio its area of influence and the total area of the basin.

\subsubsection{Potential Evapotranspiration}

Potential Evapotranspiration (PET) is one of the major inputs into rainfall- runoff model. Hargreaves the method was used for the limited of climate data available therefore this method applicable for this study area. Hargreaves method was used to estimate PET for analysis of climate change. The main inputs to this method are minimum and maximum temperature.

The equation for computation of Evapotranspiration by Hargreaves method is

$$
\text { ETo }=0.0023 * \mathrm{R}_{a} *\left(\mathrm{~T}_{a}+17.8\right) *\left(\sqrt{T_{\max }-\mathrm{T}_{\min }}\right)
$$

where; $\mathrm{ET}_{\mathrm{O}}$ is reference evapotranspiration $\left(\mathrm{mmday}^{-1}\right) ; \mathrm{T}_{\max }$ is the daily maximum temperature in $\left({ }^{\circ} \mathrm{C}\right) ; \mathrm{T}_{\min }$ is daily minimum temperature $\left({ }^{\circ} \mathrm{C}\right)$

$$
\mathrm{T}_{a}=\frac{\left(\mathrm{T}_{\max }+\mathrm{T}_{\min }\right)}{2}
$$

where Ta is the daily mean air temperature in $\left({ }^{\circ} \mathrm{C}\right)$

$$
\left.\mathrm{R}_{a}=\frac{24(60)}{\Pi} G S c d r\left[\left(\omega^{s} \sin \varphi \sin \delta\right)+\cos \varphi \cos \delta \sin \omega^{s}\right)\right](5)
$$

where: $R_{a}$ is the extraterrestrial radiation $\left(\mathrm{MJm}^{-2}\right.$ day $\left.^{-1}\right), \mathrm{G}_{\mathrm{sc}}$ is solar constant $=0.082 \mathrm{MJ}\left(\mathrm{m}^{2} \mathrm{~min}\right)^{-1}, \mathrm{dr}$ is the inverse relative distance, The evaporation in $\mathrm{mmday}^{-1}$ is obtained by multiplying $\mathrm{Ra}$ by 0.408 ; where $1 \mathrm{MJm}^{-2}$ day $^{-1}=0.408$ mmday $^{-1}$.

$$
d_{r}=0.033 \cos \left(\frac{2 \pi}{365 * J}\right)
$$

where: $\mathrm{J}$ is the number of Julian day in the year between 1 January and 365or 366 (31December).

$$
\omega^{s}=[-\tan \varphi \tan \delta]
$$

$\omega^{s}=$ Sunset hour angle 


$$
\begin{array}{r}
\delta=0.409 \sin \left(\frac{2 \pi}{365 * J-1.39}\right) \\
\varphi(\text { radians })=\frac{\pi \varphi}{180}(\text { decimal degress })
\end{array}
$$

where $\delta$ is solar declination, $\varphi$ is the latitude (radians) and it is positive in the northern hemisphere while negative in the southern hemisphere.

The downscaled minimum and maximum temperature, the PET for future time horizon is calculated by using Hargreaves method.

\subsubsection{HBV-96 Model Setup}

In HBV-96 model the parameter that are used for calibration are divided into group's soil moisture routine and response function routine. Three parameters BETA, FC and LP govern the water balance of the HBV-96 model and directly related to the base flow. Because it is easier adjust the base flow than the quick flow the soil moisture routine parameters (BETA, FC and LP) are calibrated first. Another hand Khq, HQ and alpha parameters affect the shape of the hydrograph and also the peak discharge. To obtain the optimum values for the response function routine parameters combination of Khq with Alpha done. The model parameters are calibrated within reasonable range in order to be physically meaningfully.

Finally, LP and base flow are directly proportional as the base flow decreases as LP decreases. FC and volume of discharge are inversely proportional as FC increase the volume of discharge decreases. As $\beta$ increases less water infiltrates into the soil and more runoff is created. The Perc parameter was used to adjust the level of the base flow and k4 was used to adjust the recession of the base flow. Perc and base flow are directly proportional as Perc value increases the base flow value also increases. The Khq and $\alpha$ parameters were used to adjust the peak of the hydrograph.

Many scholars used HBV-96 model for assessing impact of climate change on water resources available $[1,7,9,17]$ and they can use the HBV-96 parameters based on the catchment of the characteristic Alfa, beta, FC, Perc, K4, Khq and LP. Hq is the high flow level at which the recession rate Khq is assumed to hold. The parameters Khq, Hq and Alfa used to calculate the value of $\mathrm{k}$ assuming $\mathrm{Khq}$ to be recession rate for high flow level at Hq.

The data from some of the station does not have good quality and there is no sufficient hydrological station in the basin. Hence, transferring stream flow data to each sub-basin using area ratio method.

$$
\text { Q ungauged }=Q \text { gauged } *(\text { A ungauged } / \text { A gauged })^{n}
$$

where, Agauged is drainage area at the outlet, Aunguage is drainage area of the unguage each subbasin, Qungauged is estimated discharge and Qguage is observed discharge at outlet. $\mathrm{n}$ is a value which varies between 0.6 and $1.2 \mathrm{n}$ value of 0.95 was used for this basin.

Normally the parameter $\mathrm{Hq}$ was calculated from the mean of observed discharge over the whole period and the mean of annual peak flows. Since $\mathrm{Hq}$ was not calibrated here, its value was estimated for the entire basin and for the sub-basin of Baro basin.

$$
\mathrm{HQ}=\frac{\sqrt{\mathrm{MQ} * \mathrm{MHQ}} * 86.4}{\mathrm{~A}}
$$

where; HQ: high flow rate (mm/day), MQ: mean of the observed discharge flow over the whole period $\left(\mathrm{m}^{3} / \mathrm{sec}\right)$, MHQ: mean annual peak flows $\left(\mathrm{m}^{3} / \mathrm{sec}\right) \mathrm{A}$ : area of the catchment $\left(\mathrm{km}^{2}\right)$.

\subsubsection{HBV-96 Model Performance}

The performance analysis of the model in this study were based on Relative volume error (RVE) and Nash and Sutcliffe efficiency (NSE). The Relative Volumetric Error (RVE) is represents variation between simulated and observed discharge.

$$
R V E=\left[\frac{\sum_{i=1}^{n}(Q \operatorname{sim}, i-Q o b s, i)}{\sum_{i=1}^{n} \text { Qobs }, i}\right] * 100 \%
$$

where: Qsim represent the simulated daily discharge; Qobs represent the observed daily discharge; $i$ is a time index and $n$ refers to the number of days of the simulation period. RVE value indicates between $-5 \%$ to $5 \%$ the model performance is very good while between $-10 \%$ to $-5 \%$ and $5 \%$ to $10 \%$ suggest satisfactory performance. It can range from $-\infty$ to $+\infty$.

The Nash-Sutcliffe efficiency (NSE) is widely used and highly reliable method to evaluate the performance analysis of the hydrological model.

$$
N S E=1-\left(\frac{\sum_{i=1}^{n}\left(Q_{o b s, i}-Q_{s i m, i}\right) 2}{\sum_{i=1}^{n}(Q o b s, i-\overline{Q o b s})^{2}}\right.
$$

where: Qsim represent the simulated daily discharge; Qobs represent the observed daily discharge; $i$ is a time index and $n$ refers to the number of days of the simulation discharge period; $\overline{Q o b s}$ indicates that an average daily discharge. NSE value of 1 indicates the perfect match of simulated discharge with the observed data. It can range from $-\infty$ to 1 .

\subsection{Accuracy of Rainfall Simulations from Climate Models}

The Coefficient of Variation (CV) is the standard deviation divided by the mean rainfall amount. $\mathrm{Cv}$ was used here evaluate how well the rainfall variability by the network stations is captured and represented by the RCMs. The median of the $\mathrm{CV}$ values from the RCM grid cells in each. According to $[3,4,6,13]$ the measures are as follow:

$$
\begin{aligned}
& \text { Bias }= 100 * \frac{\overline{\text { Rrcm }- \text { Robs }}}{\overline{\mathrm{Robs}}} \\
& \mathrm{RMSE}= \sqrt{\frac{\sum_{t=1}^{N}(\text { Rrcm-Robs })^{2}}{N}} \\
& \mathrm{C} v=100 * \frac{\sigma \mathrm{Rrcm}}{\sigma \mathrm{Robs}}
\end{aligned}
$$

where:- the over-bar symbol denotes the mean statistical operation over the analysis period; $\mathrm{N}$ indicates the analysis period; $\mathrm{R}$ denotes basin-average rainfall amount on a certain year ( $\mathrm{t}$ ); subscripts $\mathrm{rcm}$ and obs indicate the rainfall amount 
obtained from either RCM simulation or the observation respectively; $\sigma$ refers to standard deviation either the RCM or observed rainfall data. $\mathrm{R}$ without subscript indicates that the statistics is estimated separately for either RCM or Gauge basin rainfall amount.

\subsection{Climate Change Impact Analysis}

For the projection of climate change, rainfall, evapotranspiration and maximum and minimum temperature data was downscaled from HadGEM2-ES, MPI-ESM-LR, EC-Earth and CM5A-MR climate models. The baseline and future stream flow that was simulated by HBV-96 model using the bias-corrected downscaled RCM data as model input. The impact of climate change on streamflow that was evaluated for the baseline period (1971-2000), mid-term 2050s (2041-2070). Here, the focus is the medium-term period, because of nearest to the current period. Since the short term is already passing and the long term is too far, also IPCC AR4, 2007 reported that there will be an increase of temperature to $2^{\circ} \mathrm{C}$ threshold, in mid period.

\subsection{Extreme Stream Flow}

Climate change impact on stream flow was analyzed statistically at monthly, seasonally and annually scale while for climate variables at annually scale for each climate model and corresponding projection scenarios. The impact of climate change on streamflow of Baro river was analyzed for change in low flow, medium flow and high flow. Change on streamflow was estimated by the relative change in annual, seasonal and monthly stream flow. Relative change is analyzed as follow:

$$
\text { Relative change }=\left(\frac{\mathrm{Q}-\mathrm{Qbasline}}{\text { Qbasline }} * 100 \%\right)
$$

where: Q the flow statistics (high, low and medium flow) that was estimated from 30 years period simulated data for future and baseline.

The $\mathrm{Q}_{10}$ value is a robust indicator for high flows and river discharge which is only exceeded $10 \%$ of the time. A negative trend in $\mathrm{Q}_{10}$ means a reduction in flood risk, and a positive trend represents an increase [2]. The $\mathrm{Q}_{90}$ value for low flows and river discharge which is exceeded $90 \%$ of the time. A negative trend $\mathrm{Q}_{90}$ decreasing and river droughts are likely to occur. A $\mathrm{Q}_{50}$ value for medium flows, indicates $50 \%$ of the time value is exceed increase of discharge may lead to increase of flood risk

\subsection{Eco-Hydrological Analysis}

This approach (Milne et al., 2002) evaluates the efficiency of water and energy use by an ecosystem, defined as the vegetation within a watershed. Actual evapotranspiration (ETa) is controlled by relative proportion and timing of available water $(\mathrm{P})$ and potential evapotranspiration (PET) type and condition of vegetation.

The ecohydrological concept that was applied in this study to check fully capture climate change impact on the catchment hydrology both discharge change signal, precipitation and actual/potential evapotranspiration change signal are consistently displayed by plotting Pex against Eex. The availability of water $(\mathrm{P})$, potential evapotranspiration (PET) and actual evapotranspiration (ETa) data for the Baro river basin was provided the opportunity to couple water and energy budgets. The method is suitable to display the results of climate change impact on catchment hydrology.

$$
\begin{aligned}
\text { Pex } & =\frac{\text { P-ETa }}{P} \\
\text { Eex } & =\frac{\text { PET-ETa }}{\text { PET }}
\end{aligned}
$$

Where: Pex is available water that are unused (i.e., in excess), describes the proportion of available water not used by the ecosystem; Eex is available energy not used for evapotranspiration; $\mathrm{P}$ is precipitation; ETa actual evapotranspiration; PET refer to potential evapotranspiration. Usually both terms (Pex\& Eex) are within the interval $(0,1]$ by dividing by the amount of available water/energy available, because ETa is generally positive, it cannot be larger than P and it is mostly smaller than PET. This indicates that the catchment ecosystem is able to optimize the use of water and energy available in the environment reducing unused water (Pex) with temperature increase [5]. Such an optimization, although not investigated in the Baro basin study area. The suitability of the catchment area for the current plant species could also be affected (McClean et al., 2005) by the projected climate change. Yira, Y. emphasized that removal of perennial vegetation leads to an increase of both excess water (Pex) and excess evaporative demand (Eex) [18]. The ecohydrologic status of the catchment, irrespective of climate model and emission scenario, projects a shift for the period of 2041-2070 compared to the reference period.

\section{Results and Discussion}

\subsection{HBV Model Simulation}

In this section, the results of this study are presented. These results include the HBV-96 model simulation, the accuracy of the simulate rainfall by the climate models and impact of climate change on climatic and hydrological variables. Also, climate change impact is presented for baseline period (1971-2000) and future periods (2041-2070). First, the calibration and validation results of the HBV model are presented.

As shown in Table 1, the value of $\mathrm{Hq}$ (the high flow rate) parameter of HBV is presented. This parameter is estimated from the stream flow data which was observed at Baro@Gambela station. To estimate the Hq value for each sub-basin there is no good quality data and sufficient hydrological station in the basin. Therefore, the observed discharge at outlet for eight sub-basin was transferred by using area ratio method. Since Hq was not calibrated here, its value was estimated for the entire basin and for the sub-basin 
of Baro basin.

Table 1. The value of MQ, MQH for the period of 1994-2005 and area of the sub-basin.

\begin{tabular}{lllll}
\hline Subbasin & $\begin{array}{l}\text { MQ } \\
\left(\mathbf{m}^{3} / \mathbf{s e c}\right)\end{array}$ & $\begin{array}{l}\text { MHQ } \\
\left(\mathbf{m}^{\mathbf{3}} / \mathbf{s e c}\right)\end{array}$ & $\begin{array}{l}\text { Hq } \\
(\mathbf{m m} / \mathbf{d a y})\end{array}$ & Area $\left(\mathbf{k m}^{\mathbf{2}}\right)$ \\
\hline 1 & 44.06 & 1653.42 & 9.78 & 2384.2 \\
2 & 50.39 & 1890.73 & 9.71 & 2745.7 \\
3 & 43.53 & 1633.32 & 9.79 & 2353.7 \\
4 & 43.24 & 1622.44 & 9.86 & 2337.2 \\
5 & 53.85 & 2020.55 & 7.77 & 2944.5 \\
6 & 65.28 & 2449.79 & 9.58 & 3606.4 \\
7 & 89.07 & 3342.24 & 9.43 & 5001.3 \\
8 & 37.93 & 1423.14 & 9.86 & 2036.0 \\
(Outlet) & 385.93 & 14481.78 & 8.73 & 23409.0 \\
\hline
\end{tabular}

The calibrated and range values of the HBV-96 model parameters of Baro basin are shown in Table 2. High field capacity $(900 \mathrm{~mm})$ suggests a deep system, which is filled slowly and generates streamflow at slow rate. The low value of Alpha indicates the slowly varying response of the catchment. Beta also has low values for the study area show slow water infiltration into the soil and more runoff is formed. Low Perc value decreases the base flow.

The NSE criterion is used to evaluate model performance in terms of capturing the pattern of the observed hydrograph. NS value between 0.9 and 1 indicate that the model performs very good while values between 0.6 and 0.8 indicate the model has good performs [17].

RVE ranges $-\infty$ to $+\infty$, where the good model RVE is $-5 \%$ and $+5 \%$ while the value between $-10 \%$ to $-5 \%$ and $+5 \%$ to $+10 \%$ are considered as reasonably well performing model. The two objective function values of Baro@Gambela outlet are 0.91 and $-6.76 \%$ during calibration period (1996-2002). These values reveal that the model performance is very good for this study. When validated for data outside the calibration period the estimated NSE and RVE values are 0.72 and $9.78 \%$. This indicates that the model performance deteriorated when evaluated for an independent period but it is still acceptable.

Table 2. The calibrated and allowable range values of the HBV-96 model parameters.

\begin{tabular}{|c|c|c|c|}
\hline Routine & Parameters [Unit] & Calibrated values & Range of values \\
\hline \multirow{3}{*}{ Soil routine } & Lp-Limit for potential evapotranspiration [-] & 0.98 & $\leq 1$ \\
\hline & Beta $[-]$ & 1.35 & $1-4$ \\
\hline & FC-Maximum soil moisture storage [mm] & 900 & $100-1500$ \\
\hline \multirow{7}{*}{$\begin{array}{l}\text { Response } \\
\text { function }\end{array}$} & K4-Recession coefficient for the lower response box $\left[\mathrm{day}^{-1}\right]$ & 0.012 & $0.001-0.1$ \\
\hline & Khq-Recession coefficient for the upper response box $\left[\right.$ day $\left.^{-1}\right]$ & 0.05 & $0.005-0.2$ \\
\hline & Alpha $[-]$ & 0.5 & $0.5-1.1$ \\
\hline & Perc-percolation rate $[\mathrm{mm} / \mathrm{day}]$ & 0.72 & $0.01-6$ \\
\hline & Objective function & Calibration & Validation \\
\hline & Nash-Sutcliffe coefficient of Efficiency (NSE) & 0.91 & 0.72 \\
\hline & Relative Volumetric error (RVE) & -6.76 & 9.78 \\
\hline
\end{tabular}

The simulated and observed hydrographs are shown in Figure 2, for the initialization, calibration and validation periods. The shapes of both hydrographs have a good agreement in terms of base flow, rising and recession limb and the peak flows. The deviation between the two hydrographs is larger in the validation than the calibration period.

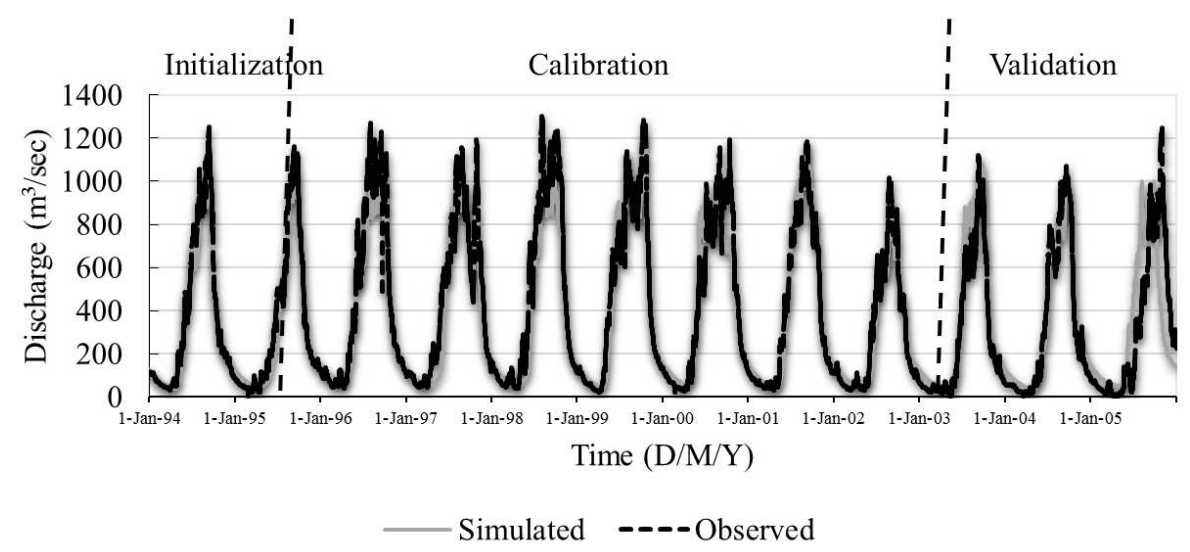

Figure 2. Daily observed and simulated hydrographs for Baro@Gambela station of Baro basin during calibration and validation periods.

\subsection{Climate Model Performance Evaluation (Evaluating the Accuracy of Climate Model Simulations)}

As shown in Table 3, the climate model simulations underestimated the observed annual rainfall. The accuracy of the climate models is not equal in representing the rainfall over the Baro basin. In terms of bias, EC-Earth performs best
$($ Bias $=-4.20 \%)$ while HadGEM2-ES performs worst $($ Bias $=$ $-25.39 \%)$. In terms of RMSE, MPI-ESM-LR performs worst $(\mathrm{RMSE}=40.74 \mathrm{~mm})$ while CM5A-MR performs best (RMSE $=61.24 \mathrm{~mm}$ ). These values indicate that the simulated rainfall over the Baro basin by large differs from the observed rainfall for all climate models. Overall, the difference between simulated and observed rainfall amounts is too large 
to ignore. Therefore, the bias should be corrected before using it for stream-flow simulation.

Table 3. Accuracy of dynamically downscaled rainfall from multiple GCMs models.

\begin{tabular}{lllllll}
\hline & Observed & EC-Earth & MPI & HadGEM2-ES & CM5A-MR & Ensemble \\
\hline Rainfall (mm) & 1724.50 & 1652.08 & 1441.90 & 1286.64 & 1388.25 & 1442.22 \\
Bias (\%) & - & -4.20 & -16.39 & -25.39 & -19.50 & -16.37 \\
RMSE (mm) & - & 49.25 & 40.74 & 51.06 & 61.24 & 31.74 \\
CV (\%) & 69.53 & 60.87 & 73.12 & 83.00 & 113.89 & 76.22 \\
\hline
\end{tabular}

Figure 3 shows that the climate models reasonably capture the annual cycle of the observed rainfall amount over the Baro basin. However, the models systematically underestimated the monthly rainfall amounts particularly between May and September, which are the wettest months. It indicates that bias correction is required for further use of the climate model' data.

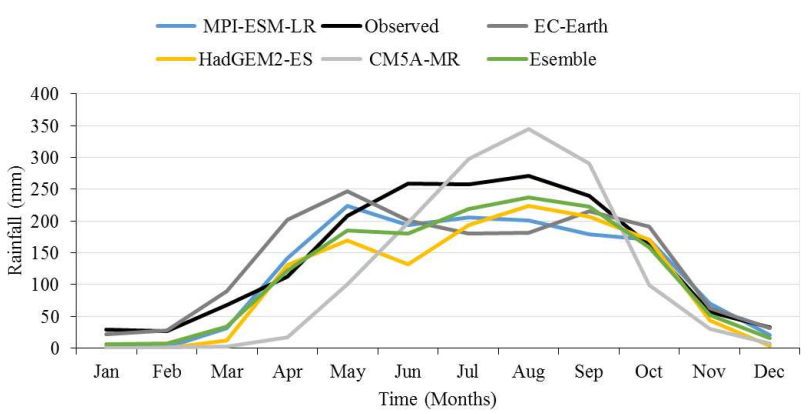

Figure 3. Annual cycle of observed and simulated rainfall amount over Baro basin (1985-2010).

\subsection{Bias Correction of Rainfall Estimates from Climate Models}

In this study, bias correction is used to correct the large systematic errors of the dynamically downscaled data from the four the GCM models' simulations under RCP 4.5. See Annex B for the estimated values of the parameters of the bias correction method which was used in this study. The performance of the bias correction method is evaluated using plot of annual cycle of rainfall for the observed and bias corrected climate models. After bias correction, the climate model simulations reasonably reproduced the observed annual rainfall over Baro basin (Figure 4). Both the magnitude and pattern of the observed annual cycle of rainfall are reasonably captured. Hence, the rainfall data can be used to evaluate climate change impacts in the Baro basin.

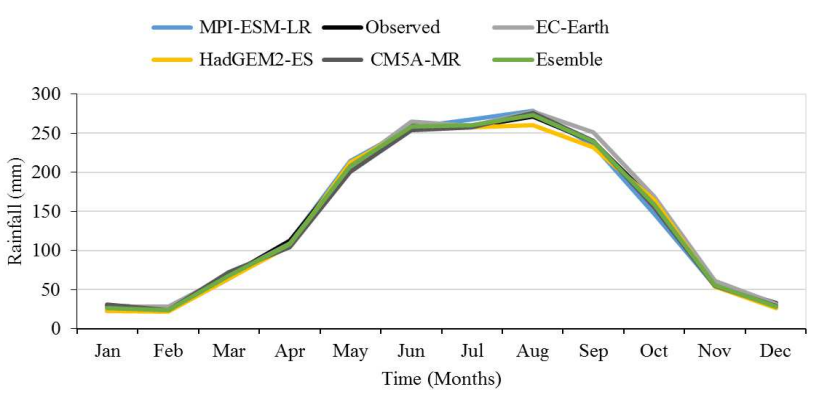

Figure 4. Annual rainfall cycle over Baro basin for bias corrected GCMRCM models (1985-2010).

\subsection{Climate Change Impact on Rainfall and Evapotranspiration of Baro Basin}

For the 2050s (2041 to 2070), all the models except for EC-Earth projected that the magnitude of average annual rainfall will decrease by $7.34 \%$ to $17.42 \%$ under RCP4.5 scenario (Figure 5). The largest decrement in annual rainfall was projected by HaDGEM2-ES and the lowest increment was projected by CM5A-MR.

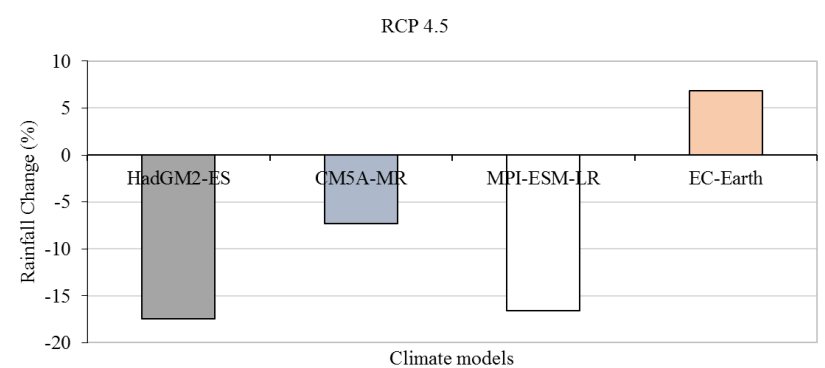

Figure 5. Annual catchment rainfall change over the period 2041-2070 under RCP4.5 scenario.

In the Baro basin there would be a change in seasonal rainfall of Belg (February, March, April and May), Kiremt (June, July, August and September) and Bega (October, November, December and January) for RCP4.5 scenario. Simulations from three of the four climate models indicated that Baro basin will face rainfall decrement for all the three seasons (Figure 6). The magnitude of the projected change in seasonal rainfall widely varies among the models'.

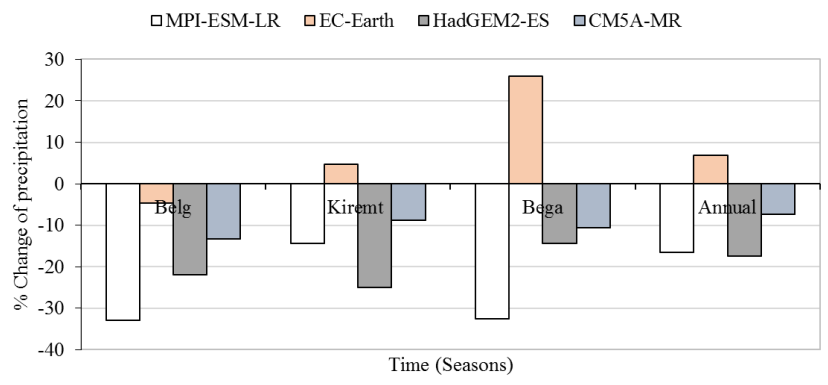

Figure 6. Seasonal rainfall changes in Baro basin over the period (20412070).

The monthly rainfall will likely decline for most months in the future as the results from the three out of four models agree in the direction of change (Figure 7). However, there will be a likely decline in rainfall amount of November. ECEarth frequently showed deviation from the projection of the other models at least in the direction of change in monthly rainfall. The percent change is largest for the rainfall of 
January to march (in excess of $40 \%$ ).

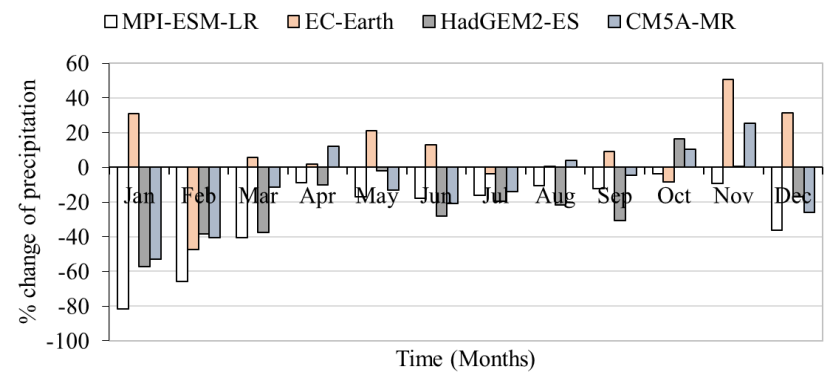

Figure 7. Change in monthly rainfall in Baro basin over the period (20412070).

Figure 8 shows the change in mean maximum temperature over the Baro basin for the period of 2041 to 2070. All models predicted that the maximum temperature will likely increase by $2.08^{\circ} \mathrm{C}$ (MPI-ESM-LR) to $2.52^{\circ} \mathrm{C}$ (CM5A-MR) under intermediate RCP4.5 scenario. The mean minimum temperature will also likely increase but there is relatively wide range of variation in the magnitude of change from the models by $1.65^{\circ} \mathrm{C}$ (EC-Earth) to $2.78^{\circ} \mathrm{C}$ (HadGM2-ES).

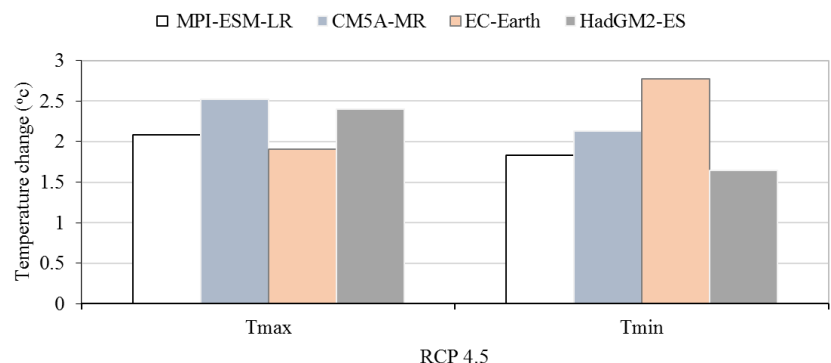

Figure 8. Average maximum and minimum temperature change over the period (2041-2070).

Figure 9 shows the maximum temperature scenario will likely increase for seasons and annually. Seasonally, the largest maximum amount of temperature increment is projected during Kiremt (June to September) for the CM5AMR by up to $3.29^{\circ} \mathrm{C}$. The mean maximum temperature large variation in magnitude will likely change by up to $1.91{ }^{\circ} \mathrm{C}$ (CM5A-MR) in Bega and up to $2.61^{\circ} \mathrm{C}$ in Belg (MPI-ESRLR). The magnitude of projected change in maximum temperature shows large difference in kirmit but show better consistency for the other two seasons and annually.

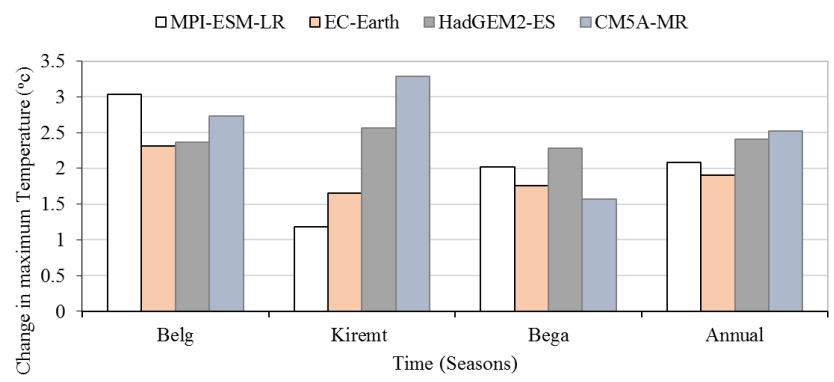

Figure 9. Seasonal maximum temperature changes in Baro basin over the period (2041-2070)
The monthly maximum temperature over the Baro basin for the Mid-term at 2050s (2041 to 2070) is also projected to increase by all models (Figure 10). All the projected increments by the models are more than $1^{\circ} \mathrm{C}$ for most months and the increments up to $3.9^{\circ} \mathrm{C}$. The models' projection showed the largest variation in magnitude for August to October.

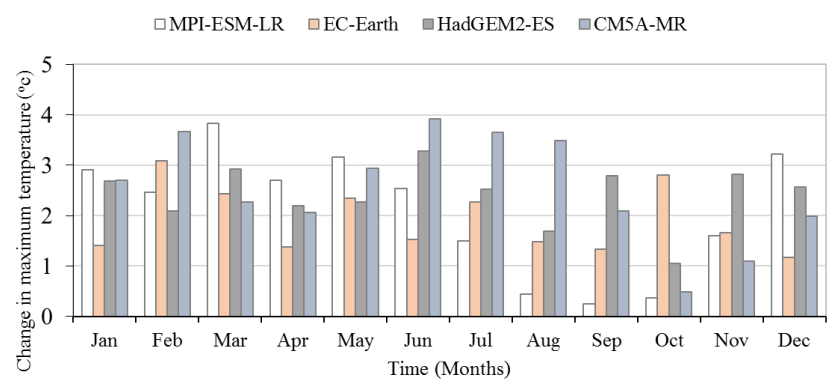

Figure 10. Monthly maximum temperature changes in Baro basin over the period (2041-2070).

As presented in Figure 11 shows the minimum temperature scenario will likely increase for all seasons and annually. Seasonally, the largest maximum amount of minimum temperature increment is projected during Kiremt (JuneSeptember) for the HaDGEM2-ES by up to $4.16^{\circ} \mathrm{C}$. The mean minimum temperature will likely shows slightly increase by $2^{\circ} \mathrm{C}$ in Belg and $2.13^{\circ} \mathrm{C}$ in Bega. The overall results the magnitude of projected change in minimum temperature shows large difference in kirmit than Belg and Bega.

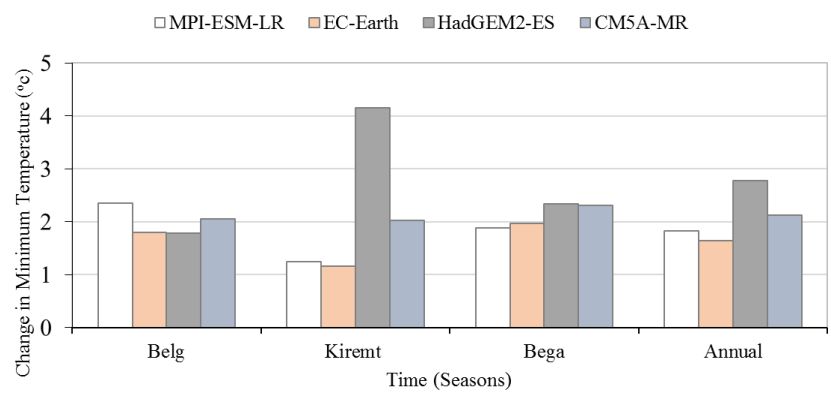

Figure 11. Seasonal minimum temperature changes in Baro basin over the period (2041-2070).

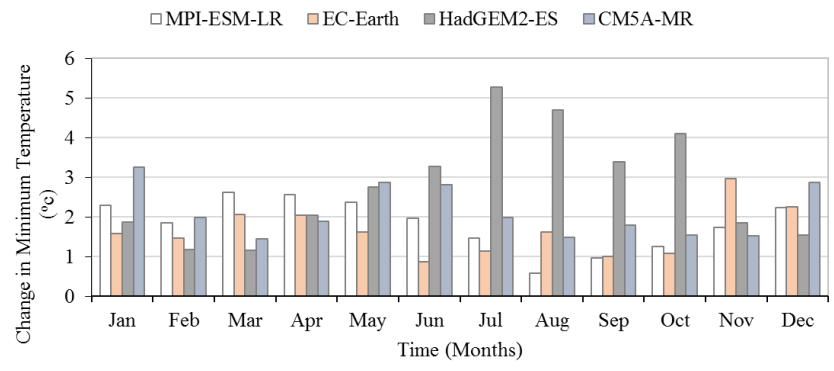

Figure 12. Monthly minimum temperature changes in Baro basin over the period (2041-2070).

For the midterm at (2041-2070) the minimum temperature projected will likely increase by all months (Figure 12). The 
largest increment of minimum temperature is shown in July (HaDGEM-ES) whereas the smallest is shown in August (MPI-ESM-LR). The EC-Earth and CM5A-MR model slightly increasing than the others for all months under RCP4.5 scenario. Therefore, minimum temperature will likely increase for all months in the future as the results of four models agree in the direction of change.

The annual average Potential Evapotranspiration (PET) at 2050s (2041 to 2070) will likely increases for all models under RCP4.5 scenario. Among all climate models the CM5A-MR model indicates the large increment by $19.92 \%$ and the HadGM2-ES model projected the smallest increment by $3.59 \%$ (Figure 13 ).

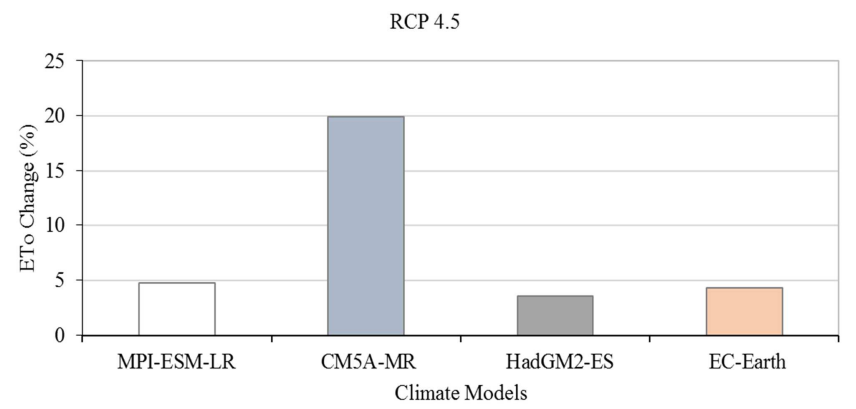

Figure 13. Annual average evapo-transpiration changes over the period (2041-2070).

It is clear that increasing in temperature has a direct impact on increasing the PET of the study area. Figure 14 clearly indicated that PET of all seasons will likely increase in the future. CM5A-MR projections show large deviation from the projections of other models. The rest of the models show that the largest increment will occur in the Belg season and with the smallest increment in Kiremt season. The annual PET will likely increase by up to $5 \%$.

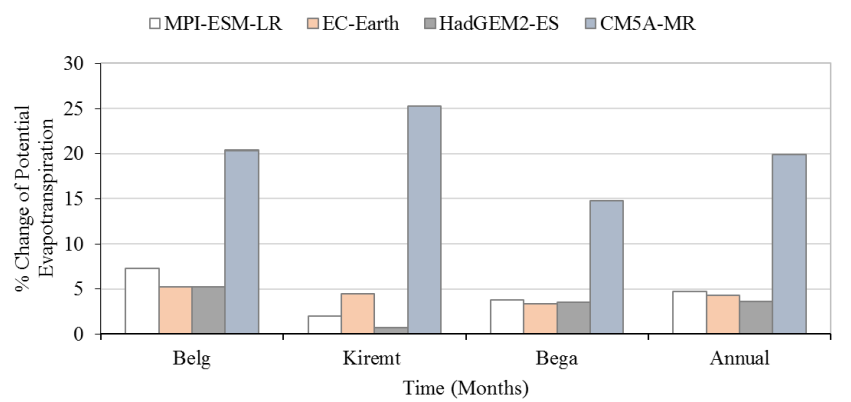

Figure 14. Seasonal PET changes in Baro basin over the period (20412070).

For the midterm at (2041-2070) the potential evapotranspiration projected will likely increase, except for HadGEM2-ES (July, August and October) and MPIESM-LR (August, September and October) (Figure 15). Potential evapotranspiration will likely increase for most months in the future as the results from the two out of four models agree in the direction of change. The largest increment is shown for July and August in the rainy season, whereas the smallest is shown towards the start of the dry season (October).
However, there is large deviation in the magnitude of projected changes by the different models.

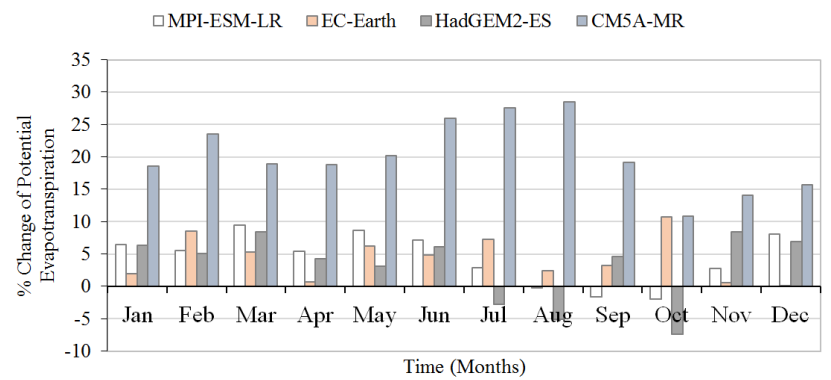

Figure 15. The projected changes in potential evapo-transpiration in Baro basin over the period (2041-2070).

\subsection{Impact of Climate Change on Streamflow}

As shown in Figure 16, results based on all models except for EC-Earth agree that the stream flow of Baro basin will likely decrease at seasonal and annual time scales. The maximum stream-flow reduction was projected during the rainy season (Kiremt) by up to $28.36 \%$ (CM5A-MR). The annual rainfall is projected to decline by up to $35.2 \%$ during 2050s. CM5A-MR consistently produced the largest magnitude of streamflow change except for the Belg season for which MPI-ESM-LR showed the largest reduction. The annual streamflow reduction consistent with the annual precipitation reduction and increased annual evapotranspiration. Therefore, the streamflow found to be sensitive to changes in both precipitation and temperature.

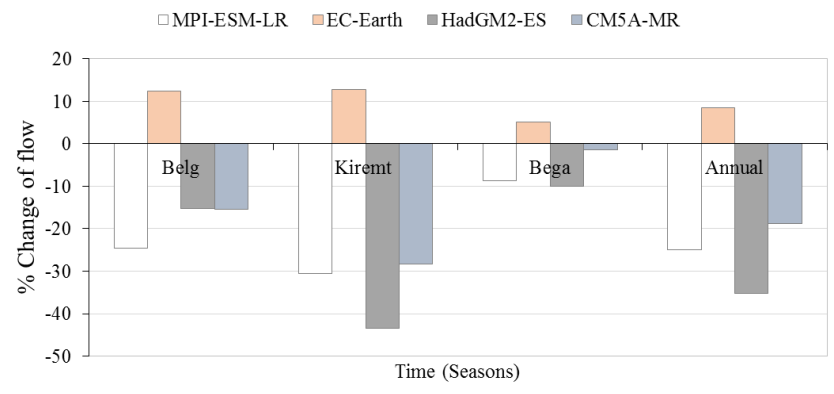

Figure 16. Change in seasonal and annual stream flow for the medium future (2041-2070) under RCP4.5 scenario.

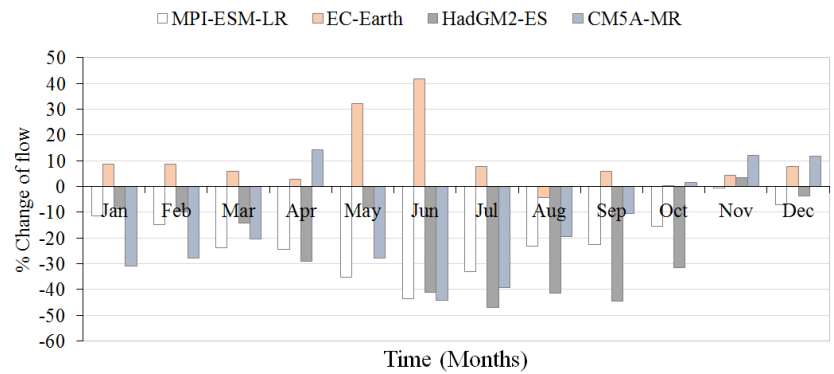

Figure 17. Monthly change in stream flow of Baro basin over the period (2041-2070).

Figure 17 shows the projected changes in streamflow for the medium period (2041 to 2070). Under RCP4.5, the streamflow of Baro will likely decline in all months except in 
November and December. This is projected by all models except for EC-Earth. The highest decrement in streamflow will occur in June and July. The flow will likely increasing November but the models' projections is not conclusive for the December flow.

\subsection{Impact of Climate Change on Extreme Flows}

Extreme streamflow (low, medium and high flow) have great importance in water resource systems. Therefore, the impact of climate change on extreme flows was analyzed for RCP 4.5 scenario under four climate models.

As presented in Table 4, the streamflow statistics four the models projected changes in high flow (Q10), medium flow (Q50) and low flow (Q90) in the 2050s with respect to the baseline under RCP4.5 scenarios. This indicates that extreme streamflow results in the Baro basin the three-climate model shows the directions will likely increase from -34.49 to $9.20 \%$ for high flow $\left(\mathrm{Q}_{10}\right)$ and the directions will likely increase between -37.49 to $4.99 \%$ for medium flow $\left(\mathrm{Q}_{50}\right)$. Also, low flow $\left(\mathrm{Q}_{90}\right)$ will likely increase from -38.84 to $16.34 \%$. And also results indicate that changes in extremes flow, it can be said that the direction of changes identified for the mean discharge holds mostly also for the high and low flow extremes.

The Table 4, shows that extreme flow model performance direction value from the statistics flow (low, medium and high flow) in the future (2041-2070) and baseline period (1971-2000). Hence, EC-Earth model is will likely increasing and the other are decreasing.

Table 4. Percent future changes in low, medium and high flows with respect to the baseline (1971-2000) under RCP4.5 scenarios in the Baro basin.

\begin{tabular}{llll}
\hline Scenario & MPI-ESM-LR & EC-Earth & HaDGEM2-ES \\
\hline Q10 & -8.69 & 9.20 & -34.49 \\
Q50 & -24.46 & 4.99 & -37.49 \\
Q90 & -38.84 & 16.34 & -34.19 \\
\hline
\end{tabular}

Q10, high flow; Q50, medium flow; Q90, low flow.

\subsection{Ecohydrological Analysis}

The Pex and Eex plot allows accurately displaying climate change impact on the catchment hydrology as main water balance components (precipitation, discharge and evapotranspiration) are presented. The shift of RCP4.5 dots (Pex and Eex) for each period are obtained from the annual average rainfall, potential evapotranspiration and actual evapotranspiration for all climate model change signal are consistently displayed.

The shift of RCP dots compared to the reference period's dot indicates the effects of climate change on the catchment hydrology. In the midterm, proportion of available water which is not used by the ecosystem (Pex) will likely increase whereas the proportion of the available energy not used for evapotranspiration (Eex) will decline (Figure 18). This implies in increase in excess water but decrease in excess energy because of climate change.

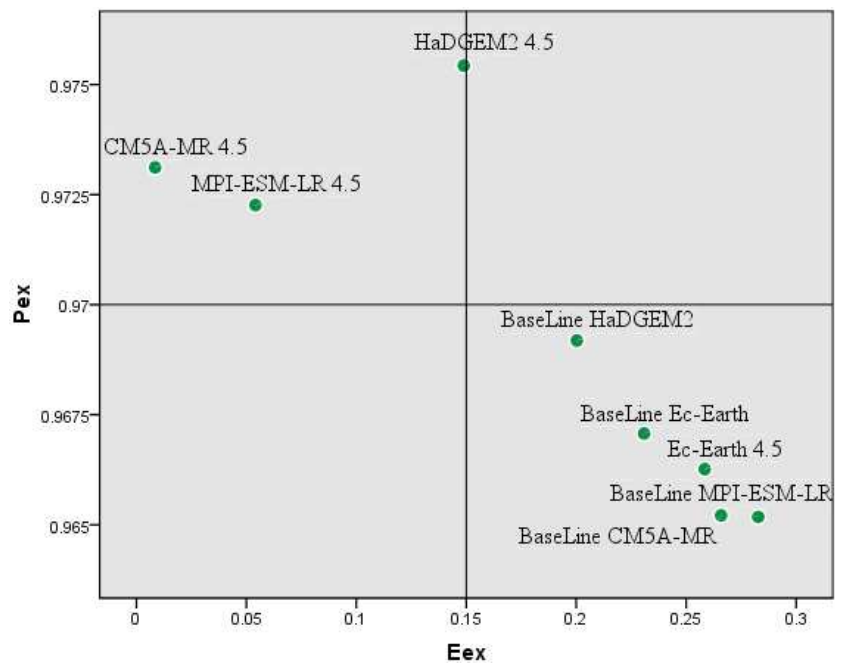

Figure 18. Plot of excess precipitation (Pex) versus evaporative demand (Eex) for the RCMs-GCMs.
The Eex versus Pex plot Figure 18 allows accurately displaying climate change impact on the catchment hydrology, as main water balance components such as precipitation, discharge and evapotranspiration are presented in an integrated manner. The overall ecohydrologic effect of climate change in the catchment as shown by the plots, is a trend towards drier environmental conditions due to increased evaporative demand (Eex). This denotes an increase in potential evapotranspiration higher than the increase in actual evapotranspiration.

The alteration of climate model RCP4.5 dots compared to the reference period's dot indicates the effects of climate change on the catchment hydrology. Pex shows significant decreases for the three climate model (EC-Earth, HadGEM2 and MPI-ESM-LR), while Eex shows a significant increase in all climate models.

\subsection{Discussions}

In this study, the projected changes (\%) in annual rainfall, streamflow and PET of the Baro basin in midterm (2041-2070) compared to the reference period the models tested under the RCP4.5 scenario. As presented in Table 5, shows projected changes in annual rainfall of the Baro basin for the medium-term (2041-2070) with 1971-2000 as reference period. The projected changes are between 17.42 and $6.83 \%$. On average, there is a slightly decrement $(8.62 \%)$ in annual rainfall for the medium future. For PET of the Baro basin, all climate models agree that it will increase in the future. The projected changes vary between 3.59 and $19.92 \%$, with the CM5AMR model showing the largest increment, whereas the HaDGEM2-ES model indicates the smallest increment. Considering that increment in PET is likely to affect soil moisture storage in the basin. 
Table 5. Projected annual changes in climate variables and streamflow in the period (2041-2070).

\begin{tabular}{llll}
\hline Climate models & Rainfall & Streamflow & PET \\
\hline HadGM2-ES & -17.42 & -35.20 & 3.59 \\
CM5A-MR & -7.34 & -18.74 & 19.92 \\
MPI-ESM-LR & -16.57 & -24.96 & 4.75 \\
EC-Earth & 6.83 & 8.50 & 4.28 \\
Ensemble & -8.62 & -17.60 & 8.14 \\
\hline
\end{tabular}

The other studies according to Haile et al., (2013) the study result is consistent (Figure 10) with in predicted temperature change reported in this study to evaluate climate change impacts on flood frequency and magnitude through continuous rainfall-runoff modeling in Baro basin. The annual minimum temperature is expected to increase by up to $2^{\circ} \mathrm{C}$ and $1.4^{\circ} \mathrm{C}$ for $\mathrm{A} 2$ and $\mathrm{B} 2$ scenarios respectively towards the end of the $21^{\text {st }}$ century. The annual maximum temperature is also expected to increase by up to $1.56^{\circ} \mathrm{C}$ and $1.2^{\circ} \mathrm{C}$ for $\mathrm{A} 2$ and $\mathrm{B} 2$ scenarios respectively. Overall the results, the higher temperature, leads to the higher potential evapotranspiration and the greater potential loss of water. Hence, the temperature increases the water demand in the basin also increases for different activities.

The other studies according to Tadesse, G. reported that the projected maximum and minimum temperature shows an increasing pattern for all future time horizons for RCP 4.5 scenarios [16]. But the mean annual rainfall data analysis revealed upward pattern in some years and downward pattern in others in all future time horizons for RCP 4.5 scenarios. The runoff is expected to change according to temperature and precipitation changes may be less runoff simulated $12.1 \%$ and $7.65 \%$ decrease in mean annual runoff in the 2021-2050 and 2051-2080 time horizon respectively for RCP 4.5 scenario.

In most case the existing literature agrees mostly on the percentage changes in flow statistics (Q10, Q50 and Q90) of the six sub-basins under the weighted runoff scenario for the 2050s. Kim, U., \& Kaluarachchi, J. J. reported that Q10 and Q50 show a similar range of percentage changes $-15 \%$ to $20 \%$, the range of changes in Q90 is much wider $-25 \%$ to $60 \%$ [11]. This result can be explained by runoff in low flow seasons, which is usually more sensitive to changes in potential evapotranspiration than runoff during high flow seasons. It is also partially because a relative percentage change value is magnitude sensitive the same increment or decrement gives a higher percentage change for low flows than for high flows. When it comes to low flows, a previous study confirmed the author agrees mostly on an increase of frequency and magnitude of river droughts. These findings are not always connected to climate change, but to the increase in water use (Aich et al., 2014; Franz et al., 2012).

\section{Conclusion and Recommendation}

\subsection{Conclusion}

In this study, the impact of climate change on stream flow was evaluated for Baro basin for 2041-2070 under RCP4.5 scenarios. HBV-96 model was used to simulate historical and future runoff using climate data obtained from HadGM2-ES, MPI-ESM-LR, CM5A-MR and EC-Earth GCM models. The data from these models was downscaled dynamically by CORDEX using CCLM, CCLM4, RCA4 and RACMO22T RCMs.

The climate change is likely to have severe effects on water availability of Baro basin. Outputs of four GCMsRCMs data, all produced in the frame of the CORDEXAfrica project, and were used as input to a hydrological simulation model to investigate climate change impact on water availability in the Baro basin by the mid- $21^{\text {st }}$ century.

The implications of the RCP4.5 scenario for outputs of four GCMs-RCMs data were used as input to a hydrological simulation model to investigate climate change impact on hydrological responses in the Baro basin. The ability of the RCMs-GCMs ensemble to simulate historical climate and discharge was evaluated prior to future climate change impact assessment. The baseline for scenario refers to the 1971-2000 period while the medium future covers 2041-2070.

According to this study, the Baro basin HBV-96 model has satisfactorily reproduced the hydrograph pattern and volume of observed streamflow outside the calibration period. As result, the calibrated model was used to simulate future streamflow of the Baro basin.

Pattern of monthly rainfall from dynamically downscaled climate data resembles with the observed rainfall for all selected climate models for Belg and Dry season except for CM5A-MR model. However, the models did not captured the observed rainfall (Bias $=-4.20 \%$ to $25.39 \%$ ). These values indicate that the simulated rainfall over the Baro basin by large differs from the observed rainfall for all climate models.

The annual rainfall will likely decrease by $7.34 \%$ to $17.42 \%$ of Baro basin under RCP4.5 for the 2050s (2041 to 2070) except for EC-Earth. This means there is contraction between the climate models with regard to the direction projected precipitation change. The maximum temperature is projected to increase by up to $2.52^{\circ} \mathrm{C}$ for the all climate models under intermediate emission RCP4.5 scenario.

The annual average Potential Evapotranspiration (PET) at 2050s (2041 to 2070) will likely increases for all models under RCP4.5 scenario. It is clear that increase in temperature has a direct impact on increasing the PET of the study area. PET will likely increase for most months in the future as the results from the two out of four models agree in the direction of change.

Significant reduction in stream flow by up to $28.36 \%$ is projected during the rainy season (Kiremt) (CM5A-MR). The annual streamflow is projected to decline by up to $35.2 \%$ during 2050s. The annual streamflow reduction consistent with the annual precipitation reduction and increased annual evapotranspiration. Therefore, the stream flow found to be sensitive to changes in both precipitation and temperature. Under RCP4.5, the streamflow of Baro will likely decline in all months except in November and December. The highest decrement in streamflow will occur in June and July. The streamflow will likely increase in November but the models' projections are not conclusive for the December flow. 
Overall, the results for the medium-term (2041-2070) suggest that, under a $2{ }^{\circ} \mathrm{C}$ global warming threshold, the magnitude of annual rainfall amount is projected to change 17.42 to $6.83 \%$. The rainfall amount of the short rainy period (Belg) is projected to reduce in the future. Annual PET is projected to increase by 3.59 to $19.92 \%$ for the medium-term and PET will increase for both the dry and wet months, with the largest increment in the wettest months. The projected changes in rainfall under RCP4.5 will result in a reduction in streamflow. Overall, this study shows the importance of using multiple climate models to understand the range of projected changes in hydrological responses in a basin.

The ecohydrological concept as applied in this study proved to fully capture climate change impact on the catchment hydrology as both discharge change signal, precipitation and actual/potential evapotranspiration change signal are consistently displayed by the Eex-Pex plot. The method is suitable to display the results of climate change impact on catchment hydrology.

\subsection{Recommendation}

Generally from this specific study the following main points are strongly recommended;

The result of this study is based four GCM-RCM model and one emission scenario due to time limitation and data availability this particular study. However, in most climate change impact assessment studies the application of different GCM model outputs under different emission scenarios are recommended in order to make comparison between different models as well as to explore a wide range of climate change scenarios that would result in different hydrological impacts. Application of different GCM outputs and emission scenarios are recommended in future extension of this study. Therefore, other researchers can do the other emission scenario for further study of climate change impact in basin.

There should be additional gauging station to record the flow and to reduce the missing flow data for further study in Baro sub-basin.

The Eco hydrological analysis approach appears suitable to display the results of climate change impact on catchment hydrology the concept is new for the country, so, it is better if it is used for further analysis.

In order to assure the development of water resource and agricultural efficiency of poor countries like Ethiopia, further studies which incorporate the impact of climate change with land use and land cover change, plus sediment inflow to the reservoirs should be undertaken by using multiple Global Circulation Models (GCMs). These studies should also investigate the adaptation options for the impact of climate change consequences in the Baro Basin.

\section{References}

[1] Abdo, K. S. (2009). Assessment of Climate Change Impacts on the Hydrology of Gilgel Abbay Catchment in Lake Tana Basin, Ethiopia. https://doi.org/10.1002/hyp.7363
[2] Aich, V., Liersch, S., Vetter, T., Huang, S., Tecklenburg, J., Hoffmann, P., Hattermann, F. F. (2014). Comparing impacts of climate change on streamflow in four large African river basins. Hydrology and Earth System Sciences, 18 (4).

[3] Alemseged, T. H., \& Tom, R. (2015). Evaluation of regional climate model simulations of rainfall over the Upper Blue Nile basin. Atmospheric Research, 161-162, 57-64. https://doi.org/10.1016/j.atmosres.2015.03.013

[4] Bokke, A. S., Taye, M. T., Willems, P., \& Siyoum, S. A. (2017). Validation of General Climate Models (GCMs) over Upper Blue Nile River Basin, Ethiopia. Atmospheric and $\begin{array}{llll}\text { Climate } & \text { Sciences, } & 07 & (01),\end{array}$ https://doi.org/10.4236/acs.2017.71006

[5] Caylor, K. K., Scanlon, T. M., \& Rodriguez-iturbe, I. (2009). Ecohydrological optimization of pattern and processes in water-limited ecosystems: A trade-off-based hypothesis. 45, 1-15. https://doi.org/10.1029/2008WR007230

[6] Chai, T., \& Draxler, R. R. (2014). Root mean square error (RMSE) or mean absolute error (MAE)? Arguments against avoiding RMSE in the literature. Geoscientific Model Development, 7 (3), 1247-1250. https://doi.org/10.5194/gmd7-1247-2014

[7] Gebre, S. L. (2015). Potential Impacts of Climate Change on the Hydrology and Water resources Availability of Didessa Catchment, Blue Nile River Basin, Ethiopia. Journal of Geology \& Geosciences, $04 \quad$ (01). https://doi.org/10.4172/2329-6755.1000193

[8] Haile, A. T. (2013). Assessment of Climate Change Impact on Flood Frequency Distributions in Baro Basin, Ethiopia. 8 (11), $1-34$.

[9] Haile, A. T., Akawka, A. L., Berhanu, B., \& Rientjes, T. (2017). Changes in water availability in the Upper Blue Nile basin under the representative concentration pathways scenario. Hydrological Sciences Journal, 62 (13), 21392149.

[10] Kebede, A., Diekkrüger, B., \& Moges, S. A. (2013). An Assessment of Temperature and Precipitation Change Projections using a Regional and a Global Climate Model for the Baro-Akobo Basin, 4 (1), 1-12. Earth Science \& Climatic Change.

[11] Kim, U., \& Kaluarachchi, J. J. (2009). Climate change impacts on water resources in the upper Blue Nile River Basin, Ethiopia. In Journal of the American Water Resources Association (Vol. 45). https://doi.org/10.1111/j.17521688.2009.00369.x

[12] Lafon, T., Dadson, S., Buys, G., \& Prudhomme, C. (2013). Bias correction of daily precipitation simulated by a regional climate model: A comparison of methods. International Journal of Climatology, 33 (6), 1367-1381. https://doi.org/10.1002/joc.3518

[13] Mekonnen, D. F., \& Disse, M. (2016). Analyzing the future climate change of Upper Blue Nile River Basin (UBNRB) using statistical down scaling techniques. Hydrology and Earth System Sciences Discussions, 1-27. https://doi.org/10.5194/hess-2016-543

[14] Molla, S., \& Abdisa, T. (2018). Investigating Climate Change Impact on Stream Flow of Baro-Akobo River Basin. A Case Study of Baro Catchment. 6 (5). 
[15] Sheridan, S. C., \& Allen, M. J. (2015). Changes in the Frequency and Intensity of Extreme Temperature Events and Human Health Concerns. Current Climate Change Reports, 1 (3), 155-162. https://doi.org/10.1007/s40641-015-0017-3

[16] Tadesse, G. S. (2017). Rainfall Runoff Modelling For The Ungauged Baro-Akobo Basin Sub Watersheds Under Changing Climate MSc Thesis.

[17] WaleWorqlul, A., Taddele, Y. D., Ayana, E. K., Jeong, J.,
Adem, A. A., \& Gerik, T. (2018). Impact of climate change on streamflow hydrology in headwater catchments of the upper Blue Nile Basin, Ethiopia. Water (Switzerland), 10 (2). https://doi.org/10.3390/w10020120

[18] Yira, Y., Diekkrüger, B., Steup, G., \& Bossa, A. Y. (2017). Impact of climate change on hydrological conditions in a tropical West African catchment using an ensemble of climate simulations. 2143-2161. https://doi.org/10.5194/hess-21-21432017 